\title{
Altered Immune Response to Decellularized Porcine Small Intestinal Sub- Mucosa (DPSIS) Graft in Dogs Suffering from Keratoconjunctivitis Sicca
}

\author{
Sowbharenya Chelladurai ${ }^{1}$, Kiranjeet Singh ${ }^{1}$, Aswathy Gopinathan ${ }^{1 "}$, Ravi Kant Agrawal ${ }^{2}$, \\ Pawan Kumar ${ }^{3}$, Naveen Kumar ${ }^{1}$ and Monalisa Sahoo ${ }^{3}$ \\ ${ }^{1}$ Division of Surgery, ICAR-IVRI, Izatnagar, Bareilly, Uttar Pradesh, INDIA \\ ${ }^{2}$ Division of Livestock Products Technology, ICAR-IVRI, Izatnagar, Bareilly, Uttar Pradesh, INDIA \\ ${ }^{3}$ Division of Pathology, ICAR-IVRI, Izatnagar, Bareilly, Uttar Pradesh, INDIA \\ "Corresponding author: A Gopinathan; E-mail: aswathykiran77@gmail.com
}

Received: 01 March, 2021

Revised: 20 April, 2021

Accepted: 24 April, 2021

\begin{abstract}
Study was conducted to explore immune response to decellularised porcine small intestinal sub-mucosa (DPSIS) graft though clinical evaluation and mRNA expression of selected genes of ocular surface epithelium after corneal surface reconstruction in dogs suffering from Keratoconjunctivitis sicca (KCS). Sixteen client-owned dogs that underwent deep lamellar keratoplasty (DALK) and DPSIS graft for corneal surface reconstruction were selected; seven dogs with corneal ulcer were included in group A as control and nine dogs with corneal ulcer as a complication of KCS were included in group B as treatment group. Healing of corneal ulcer under graft was evaluated clinically and by digital photographs. Gene expression of ICAM-1, VCAM-1, PD-L1 and FASL before and after grafting was done by real-time polymerase chain reaction (qRT-PCR) at definite intervals post graft. DPSIS graft promoted effective healing of corneal defect of partial/full thickness in group A and preserved corneal integrity whereas fibrosis and corneal pigmentation ensued in group B post DPSIS graft. Gene expression of ICAM-1 and VCAM-1 were found elevated in group B before and after PSIS grafting. PD-L1 mRNA expression was significantly increased in group B. Protein and gene expression of ICAM-1 and VCAM-1 varied with severity of inflammation in corneal surface post DPSIS grafting. Enhanced mRNA expression of PD- L1 and inflammatory mediators ICAM-1 and VCAM-1 in the ocular surface epithelial cells suggested an altered immune response to DPSIS graft and warranted strategies to modify them for successful repair of corneal epithelial defects in KCS affected dogs.
\end{abstract}

\section{HIGHLIGHTS}

(0 Ocular surface epithelial cells of dogs with KCS showed increased gene expression of PD-L1, ICAM-1, and VCAM-1.

0 Fate of DPSIS graft in cornea of KCS affected dogs is influenced by its altered immune status.

Keywords: Corneal reconstruction, DPSIS graft, dog, Keratoconjunctivitis Sicca

Keratoconjunctivitis sicca is an immune mediated disease affecting lacrimal gland causing dryness and chronic inflammation of ocular surface (John et al, 2018, Swapna et al., 2020, Kumar et al., 2020, John et al., 2020). Corneal ulcer is a frequently encountered complication of KCS in Pugs (John et al, 2018). Porcine Small intestinal sub mucosa (PSIS) is an alternative biomaterial to corneal graft that is easier to procure and preserve. Decellularised porcine small intestine sub-mucosa (DPSIS) has been successfully used for corneal reconstruction in veterinary practice
(Sangeetha et al., 2016 Singh et al., 2016, Sowbharenya et al., 2019); more importantly in melting corneal ulcer in dogs. It has good tensile strength, is non-immunogenic and promotes corneal wound healing by providing a collagen scaffold to be replaced by autologous tissue (Kropp

How to cite this article: Chelladurai, S., Singh, K., Gopinathan, A., Agrawal, R.K., Kumar, P., Kumar, N. and Sahoo, M. (2021). Altered immune response to decellularized porcine small intestinal sub-mucosa (DPSIS) graft in dogs suffering from Keratoconjunctivitis sicca. J. Anim. Res., 11(2): 231-240.

Source of Support: None; Conflict of Interest: None 
and Cheng, 2000). Corneal graft acceptance in already immune-compromised or inflamed graft bed such as in KCS can be challenging (Amouzegar et al., 2016). Graft uptake in cornea largely depends on the graft bed of the recipient; inflamed graft bed invariably causes corneal graft rejection (Featherstone et al., 2001). Adverse immunologic response by allogeneic and xenogeneic ECM scaffold material can be minimized by decellularization and/or chemical cross linking (Goulle, 2012). Decellularization of PSIS efficiently removes most cell nuclei and residual DNA, while preserves the non-fibrillar ECM components and the tissue optical properties (Goulle, 2012). Earlier study with PSIS graft showed pronounced corneal pigmentation in brachycephalic dogs with deep corneal ulcers (Turner et al., 2007). By the advent of molecular biological techniques, many biologically active molecules including pro-inflammatory cytokines and apoptotic/ cell cycle factors can be identified and compared. Comparative gene expression allows identification of novel genes has got important role in the ocular epithelial physiology with respect to graft acceptance/rejection (Chelladuraai, et al., 2019). Immune tolerance to DPSIS graft in host cornea is explored in this study through mRNA expression of selected genes of ocular surface epithelium after corneal surface reconstruction with decellularised porcine small intestinal sub mucosa (DPSIS) in dogs suffering from Keratoconjunctivitis sicca (KCS).

\section{MATERIALS AND METHODS}

\section{Preparation of DPSIS and surgical procedure}

Fresh samples of porcine jejunum were collected from local slaughter house, cut open into lengths of $20 \mathrm{~cm}$ in sterile slabs and were scraped gently on both sides to obtain sub mucosa. Sub mucosa thus obtained was made acellular by agitating the tissue in 1\% sodium dodecyl sulphate (SDS) for $12 \mathrm{~h}$ and disinfected with $70 \%(\mathrm{v} / \mathrm{v})$ ethanol for $12 \mathrm{~h}$ (Singh et al., 2016; Sowbharenya et al., 2019). The sections were thoroughly rinsed in $1 \mathrm{X}$ PBS between treatments and stored at $-20^{\circ} \mathrm{C}$ in $1 \mathrm{X}$ PBS solution containing antibiotics. Decellularization was then evaluated by histology, quantitative estimation of DNA content and cell viability (MTT assay). Permission to perform clinical study was obtained from Committee for the Purpose of Control and Supervision of Experiments on Animals, Ministry of environment, Forest and climate change, Government of India (No.F.25/33/2016-CPCSEA dated 16/02/2017). Written consent of the owner was taken for operative procedures as well as pre- and post-operative ocular surface epithelial cells collection. The study was conducted on sixteen client owned dogs presented to Referral Veterinary Polyclinic cum TVCC, IVRI, Izatnagar, Bareilly, Uttar Pradesh with varying degrees of corneal epithelial/stromal defect. Power calculation was not attempted for this study because of limitation in number of cases which had opted for lamellar keratoplasty. Detailed standard ophthalmic examination protocols was carried out with tonometer (Schiőtz C, Riester, Germany) Direct ophthalmoscope (Reister, Germany) and indirect ophthalmoscope (Appasamy Associates, Chennai) with a 20D indirect lens (Volk optical Inc,USA), Slit lamp Biomicroscope (Appasamy Associates, Chennai), Goniolens (OptiTech eye care, Tarun enterprises, Allahabad) along with Schirmer tear testing (STT) (Schirmer tear test ophthalmic strips, (OptiTech eye care, tarun enterprises, Allahabad) and fluorescein staining (OptiTech eye care, Tarun enterprises, Allahabad) to assess the integrity of cornea. Clinical evaluation of parameters such as menace response, transparency of cornea, degree of corneal opacity, conjunctival hyperaemia, and corneal neovascularisation was scored. Animals were divided into two groups. Group A consisted of seven dogs with corneal defect due to injury / dermoid and was not suffering from KCS. Group B consisted of nine dogs having corneal ulcer due to KCS as underlying pathology; cases that were under specific treatment for KCS with immune suppressants were excluded from study in order to avoid treatment bias. General physical examination and complete blood count (CBC) was carried out to rule out any ocular manifestation of systemic diseases.

Food and water were withheld for 12 hours prior to anaesthetic induction in all cases. Topical antibiotic (Ofloxacin - Zenfox, Mankind Pharma Ltd, New Delhi)), anti-inflammatory (Flurbiprofen - Flur, Allergen India Pvt. Ltd.) drops were instilled 6 to 24 hours prior to surgery. Surgery was performed under routine general anaesthesia and local instillation of proparacaine eye drops (Propcaine, Cipla 1td, India). Ocular surface of operated eyes was douched with $0.2 \%$ povidone iodine solution prior to surgery. Loosely adhered corneal epithelium was removed with fine colibri forceps and keratotome (3.2 mm) 
(OptiTech eye care, Tarun enterprises, Allahabad). Corneal tissue that appeared nonviable and tissues such as fibrin protruding through the defect were trimmed with corneal scissors. A corneal trephine $(6 \mathrm{~mm})$ was used to outline the lamellar keratectomy margins. A partial thickness superficial keratectomy was performed with corneal trephine approximately of the same size as that of DPSIS graft. The grafts were secured with simple interrupted sutures using $8 / 0$ polyglactin 910 , the rough surface of the graft was kept facing the corneal defect. Subconjunctival injection of Gentamicin and Dexamethasone was given immediately after surgery. Temporary tarsorraphy was done using 2-0 polyamide after DPSIS graft in both groups. Antibiotic (Ceftriaxone@20 mg/ kg body weight) and anti-inflammatory agent (Meloxicam @ $0.05 \mathrm{mg} / \mathrm{kg}$ body weight) was administered intramuscular postoperatively for 5 days. Ophthalmic drops Atropine (0.01\% TROPIN, Raymed Pharmaceuticals Ltd), antibiotic (Ofloxacin - Zenfox, Mankind Pharma Ltd, New Delhi)), antiinflammatory (Flurbiprofen - Flur, Allergen India Pvt. Ltd.) and topical cyclosporin drops (Hydroeyes $0.05 \%$ w/v, Lupin Ltd., Mumbai) were instilled thrice daily for four weeks. Tarsorrhapy sutures were removed on $15^{\text {th }}$ postoperative day. The efficacy of the bio-engineered PSIS for reconstruction of corneal defects was evaluated with Slit lamp Bio-microscope and indirect ophthalmoscope on 15,30 and 60 days postoperatively.

\section{Clinical evaluation and scoring}

The efficacy of the bio-engineered PSIS for the reconstruction of partial thickness corneal defects was evaluated based on the following parameters. Different parameters for corneal healing were recorded and graded. Scoring of Menace response was done on 1 to 3 score, $1=$ absent, 2 = Sluggish and $3=$ Present. Transparency of cornea was scored as $1=$ severe, dense opacity completely obscuring inner ocular structure; $2=$ moderately dense opacity partially obscuring inner ocular structure; $3=$ Mild haze of minimal density; $4=$ Trace or faint corneal haze and $5=$ clear cornea. Conjunctival hyperaemia was scored as $1=$ absent, $2=$ Mild, $3=$ Moderate and $4=$ Severe. Scoring of Corneal neovascularisation was recorded as 1 = No neovascularisation; 2 = Maximum vessels reaching less than one-third the distance between the limbus and corneal centre; 3 = Maximum vessels reaching between one and two-third the distance between the limbus and corneal centre; 4 = Maximum vessels reaching more than two-third the distance between the limbus and corneal centre and $5=$ Maximum invasion reaching the corneal centre. Scoring of Pupillary Light reflexes was done as $1=$ absent; $2=$ sluggish and $3=$ present. Schirmer tear testing recoded as severe $\mathrm{KCS}=</=5 \mathrm{~mm} / \mathrm{min}$; moderate to mild $\mathrm{KCS}=6-10 \mathrm{~mm} / \mathrm{min}$; mild $/$ subclinical $\mathrm{KCS}=$ $11-14 \mathrm{~mm} / \mathrm{min}$ and normal $=>/=15 \mathrm{~mm} / \mathrm{min}$ reading on Schirmer tear strip. Scoring for corneal epithelial defects based on fluorescein dye retention was done as $1=$ No dye uptake; $2=<25 \%$ staining of original wound; $3=$ $25 \sim 50 \%$ staining of original wound; $4=50 \sim 75 \%$ staining of original wound; $5=>75 \%$ staining of original wound. Digital colour photographs of cornea were taken from same distance by a single observer at different post-DPSIS graft intervals and were subjectively analysed for corneal healing on days 15, 30 and 60. In addition to above said parameters, eyes were also tested for PLR, IOP, corneal oedema, in addition to blepharospasm, pain, itching and problem free navigation outside familiar environment.

\section{Ocular surface epithelial cell collection, RNA isolation and quantification}

Ocular epithelial cell collection was done prior to and after grafting on days 15, 30 and 60 (Chelladuraai et al., 2019). Nitrocellulose membrane (Mixed Cellulose Ester Membrane, size of the pore: $0.22 \mu \mathrm{m}$, diameter GSWP: Merck Millipore Ltd. IRL) of diameter $4.5 \mathrm{~mm}$ was punched and sterilized in a polyethene zip bag $\left(2^{\prime \prime} \times 2\right.$ " $)$. The punched membrane was directly applied on the four quadrants of the conjunctiva/ocular surface, two on each quadrant and allowed to remain in contact with the eye for approximately 5-10 seconds and then peeled off with a forceps. The samples were preserved in a properly sterilized and $0.1 \%$ DEPC treated $2 \mathrm{ml}$ Eppendorf tubes with RNA later and stored at $-60^{\circ} \mathrm{C}$ deep freezer until RNA isolation. RNA was isolated using the conventional TRIzol method. Isolated RNA was then dissolved in $20 \mu \mathrm{l}$ of RNAse-free water and concentration was determined by Nanodrop (Model-ND 100, Thermo Scientific, USA) and stored at $80^{\circ} \mathrm{C}$. cDNA was synthesized from the mRNA using Verso cDNA Synthesis kit (Thermo Scientific, California), following the manufacturer's instructions. The concentration of cDNA synthesized from the various samples varied from 100 to $1000 \mathrm{ng} / 20 \mu \mathrm{L}$. cDNA aliquots $(8 \mathrm{ng} / \mu \mathrm{L})$ were prepared with nuclease free water and kept 
in deep freezer at $-20^{\circ} \mathrm{C}$. Primers of ICAM-1, VCAM-1, PD-L1 and Fas-L specific for dogs were designed using the software PrimerQuest, Integrated DNA Technologies [http://www.idtdna.com/SciTools/SciTools.aspx] with sequence data from the NCBI database and were chemically synthesized from Integrated DNA Technologies. Real time PCR (qRT-PCR) was used to identify relative mRNA expression of ICAM-1, VCAM-1, PD-L1 and FASL genes on ocular surface epithelium. Quantitative real time PCR (qPCR) was performed in CFX connect ${ }^{\mathrm{TM}}$ Real time PCR system (Bio Rad, USA). The cDNA of samples was amplified on the same plate for all four genes to ensure equal amplification conditions. Specificity of amplification products was confirmed by melting curve analysis. Results were documented as cycle threshold (CT) values. GAPDH was used as internal control for gene expression in ocular surface epithelial cells. The relative fold change values were calculated based on average normalized CT values $(\triangle \mathrm{CT})$. Relative expression of each sample was calculated using the $2^{-\Delta \Delta C T}$ method with control group as calibrator and $\log _{2}$ fold change was plotted.

\section{Western blotting}

Equal volume of pooled tear fluids was collected prior to and post PSIS graft on days 15, 30 and 60 were run on $12 \%$ sodium dodecyl sulphate (SDS)-polyacrylamide gel. Resolved proteins were transferred to a polyvinylidene difluoride (PVDF) membrane using a semi dry blotting apparatus (Bio-Rad) in $1 \mathrm{X}$ transfer buffer at a constant current of $80 \mathrm{~mA}$ for $1 \mathrm{~h}$. The unbound surface of the membrane was blocked overnight with $3 \%$ BSA at $4{ }^{\circ} \mathrm{C}$. Blocked membrane was washed 3 times with PBSTween $(0.05 \%)$ for ten min, was treated with primary antibody for ICAM-1 (1:500; Chongqing Biospes Co., Ltd, Chongqing, China) and VCAM-1 (1:1,000; Novus Biologicals, Littleton, USA), and was incubated for 6 hours. It was washed again with PBS-Tween (0.05\%) 3 times for ten minutes. Finally, the membrane was treated with horse radish peroxidase conjugated goat anti-rabbit IgG (Chongqing Biospes Co., Ltd) @ 1:1000 dilution and mouse IgGk (Santa Cruz Biotechnology Inc.) @ 1:1000 dilution and were incubated at $37^{\circ} \mathrm{C}$ for $2 \mathrm{~h}$. The blotting membrane was washed 3 times with TBS-Tween and subsequently developed with DAB solution.

Data were analyzed with software Statistical Program for
Social Sciences (SPSS 20 IBM). One way ANOVA was used to compare parametric data at different time intervals between two groups. Non-parametric data were analysed using Kruskal Wallis test, $\mathrm{p}<0.05$ was considered to be statistically significant. Graphs were prepared in Graph Pad Prism (Version 5).

\section{RESULTS AND DISCUSSION}

Porcine small intestinal sub mucosa after decellularization with $1 \%$ SDS (ionic biological detergent) macroscopically appeared as soft, spongy and glistening membrane (Fig. 1a). Histological assessment of DPSIS confirmed absence of lamina propria, tunica muscularis and cellular elements under haematoxylin and eosin staining (Fig. 1b). DNA content of DPSIS was significantly less $(\mathrm{P}<0.05)$ as compared to the native tissue indicating effective removal of cells from the native tissue (Fig. 1c). MTT assay revealed cyto-compatibility of DPSIS and cell viability was found least affected after 7 days of culture (Fig. 1d). Cells were able to metabolize the MTT substrate, which indicated that cell's mitochondria were functional when allowed to grow over DPSIS, and no adverse effects were found on cell viability and proliferation.

Group A consisted of non descript dogs (3), Labrador (3) and Pomeranian (1) whereas in Group B mostly Pugs. Age of dogs ranged from seven months to six and a half years in group $\mathrm{A}$ (mean $\pm \mathrm{S}$.E. value of age $3.75 \pm 1.05$ years) and from six months to five years in group $B$ (mean \pm S.E. value of age $2.44 \pm 0.55$ years). Detailed Clinical data of Group A and Group B dogs subjected to DPSIS graft is enlisted (Table 1). Corneal wound healing was evaluated by bio microscopy post graft in both groups for integration of DPSIS graft with host cornea on days 15, 30 and 60 . Corneal neovascularisation was observed in both groups until 20 - 30 days of grafting (Fig. 2a). Menace response was better in group A compared to Group B preoperatively and post DPSIS graft on day 60. The scaffold of DPSIS over cornea can impair menace response until its complete integration into host cornea (Fig. 2b). Menace response was absent in five out of nine dogs in group B due to corneal opacity till 30 days post-DPSIS graft. There was significant increase $(\mathrm{P}<0.05)$ in corneal transparency in group A on day 30 and day 60 (Fig. 2c). In group B, most of the animals developed pigmentation over the entire corneal surface completely obscuring anterior 


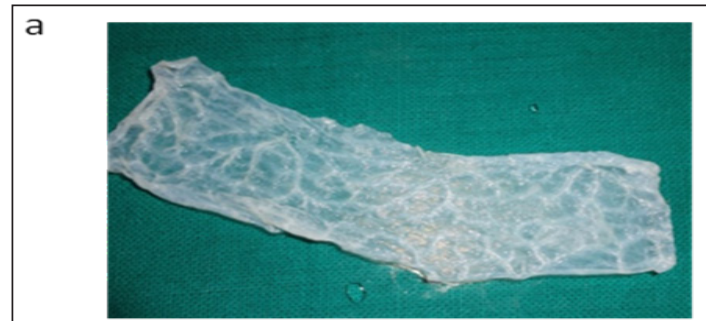

Macroscopic appearance of DPSIS

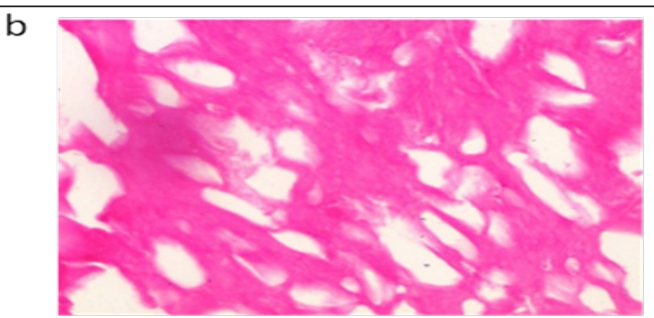

Histology of DPSIS (H\&E: 20X)

d

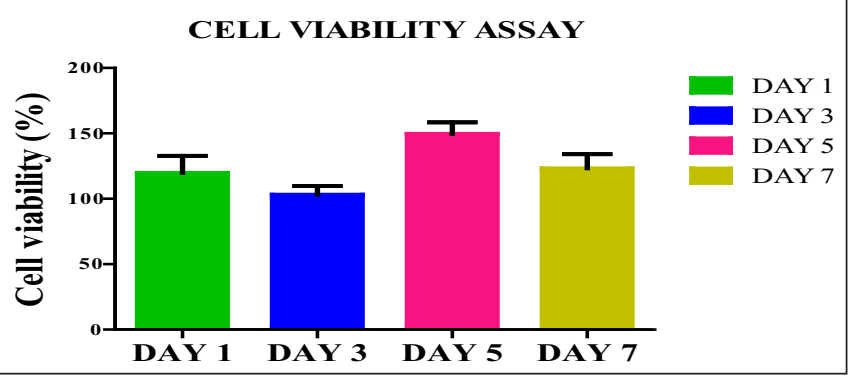

Fig. 1: Macroscopic appearance of DPSIS with a smooth glistening outer surface and rough inner surface (a), histological evaluation (H\&E: 20X) showing lack of cellular and nuclear elements (b) DNA quantification of native PSIS and decellularised PSIS (c) and MTT assay of D PSIS showing cell viability (d)

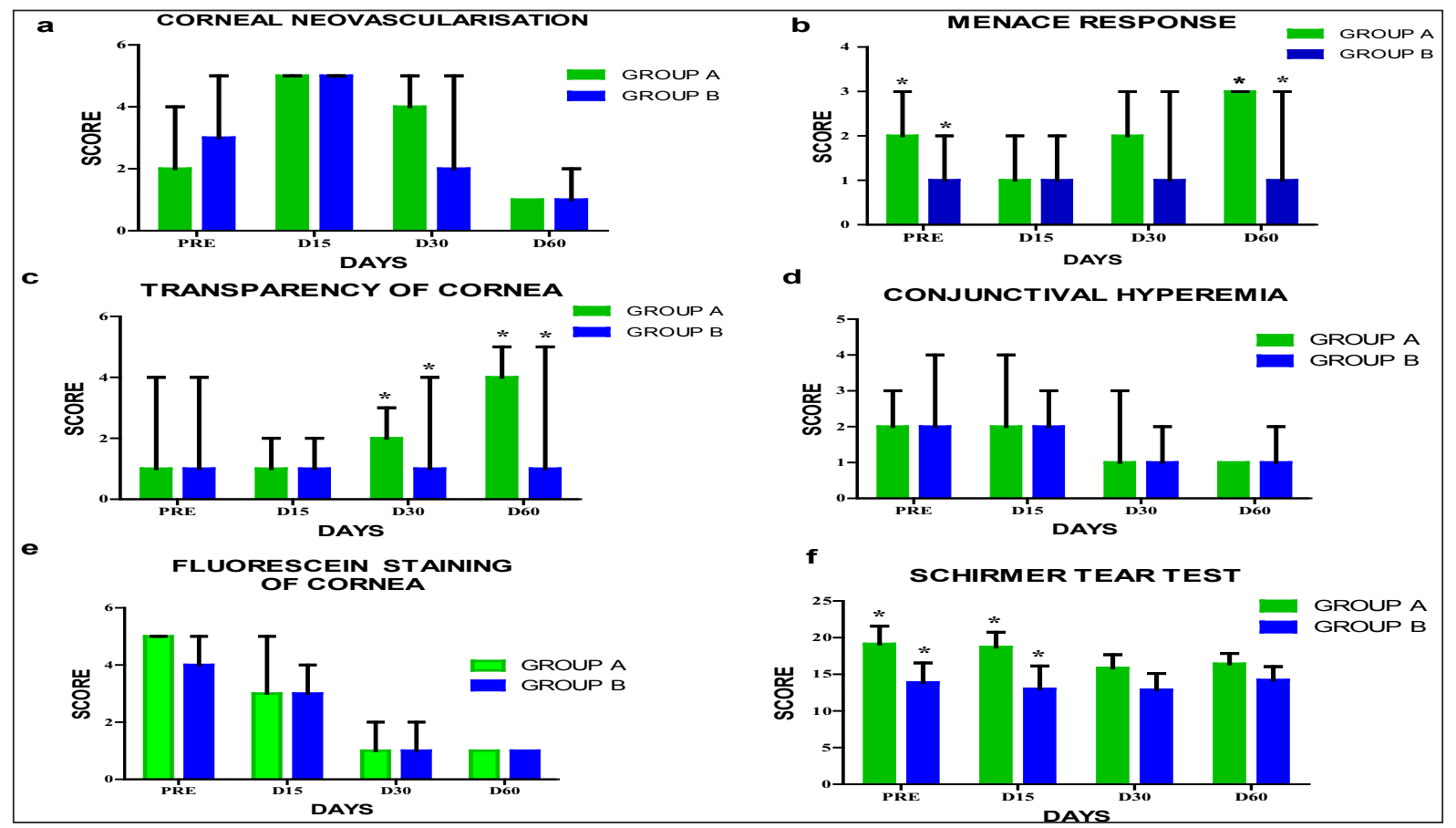

Fig. 2: Corneal neovascularisation (a) Menace response (b) transparency of cornea (c) conjunctival hyperaemia (d) fluorescein staining of cornea (e) Schirmer tear test (f) in Group A and Group B before and on days 15, 30 and 60 post-DPSIS graft; significant difference $(\mathrm{p}<0.05)$ in subjective scores depicted by asterisk mark 
Table 1: Clinical data of Group A and Group B dogs subjected to DPSIS graft

\begin{tabular}{|c|c|c|c|c|c|c|c|c|c|}
\hline $\begin{array}{l}\text { Anim. } \\
\text { no. }\end{array}$ & OD/OS & $\begin{array}{l}\text { Blink } \\
\text { reflex }\end{array}$ & $\begin{array}{l}\text { Transparency of } \\
\text { cornea }\end{array}$ & $\begin{array}{l}\text { Conjunctival } \\
\text { ingection \& } \\
\text { chemosis }\end{array}$ & $\begin{array}{l}\text { Oedema of } \\
\text { the peripheral } \\
\text { cornea \& iritis }\end{array}$ & $\begin{array}{l}\text { Corneal } \\
\text { neovascularisation } \\
\text { (Between limbus and } \\
\text { corneal center) }\end{array}$ & PLR & STT & $\begin{array}{l}\text { FDT \& } \\
\text { RBT }\end{array}$ \\
\hline A-1 & OD & Absent & $\begin{array}{l}\text { Severely dense } \\
\text { opacity }\end{array}$ & Absent & Severe & $\begin{array}{l}\text { Maximum reach between } \\
1 / 3 \& 2 / 3 \text { the distance }\end{array}$ & Absent & 20 & $>75 \%$ \\
\hline A-2 & OD & Absent & $\begin{array}{l}\text { Severely dense } \\
\text { opacity }\end{array}$ & Mild & Severe & $\begin{array}{l}\text { Maximum reach more } \\
\text { than } 2 / 3 \text { the distance }\end{array}$ & Absent & 20 & $>75 \%$ \\
\hline A-3 & OD & Absent & $\begin{array}{l}\text { Severely dense } \\
\text { opacity }\end{array}$ & Moderate & Severe & $\begin{array}{l}\text { Maximum reach less than } \\
1 / 3 \text { the distance }\end{array}$ & Absent & 20 & $25-50 \%$ \\
\hline$A-4$ & OS & Present & Faint corneal haze & Mild & Moderate & No neovascularisation & Sluggish & 22 & $>75 \%$ \\
\hline A-5 & OS & Sluggish & Faint corneal haze & Mild & Mild & $\begin{array}{l}\text { Maximum reach less than } \\
1 / 3 \text { the distance }\end{array}$ & Absent & 24 & $>75 \%$ \\
\hline A-6 & OD & Present & Faint corneal haze & Mild & Moderate & $\begin{array}{l}\text { Maximum reach less than } \\
1 / 3 \text { the distance }\end{array}$ & Sluggish & 23 & $>75 \%$ \\
\hline A-7 & OD & Present & $\begin{array}{l}\text { Mild haze of } \\
\text { minimal density }\end{array}$ & Mild & Mild & No neovascularisation & Sluggish & 5 & $>75 \%$ \\
\hline B-1 & OS & Absent & $\begin{array}{l}\text { Severely dense } \\
\text { opacity }\end{array}$ & Mild & Severe & No neovascularisation & Absent & 20 & $>75 \%$ \\
\hline B-2 & OD & Absent & $\begin{array}{l}\text { Severely dense } \\
\text { opacity }\end{array}$ & Mild & Moderate & $\begin{array}{l}\text { Maximum reach more } \\
\text { than } 2 / 3 \text { the distance }\end{array}$ & Absent & 20 & $>75 \%$ \\
\hline B-3 & OD & Absent & $\begin{array}{l}\text { Severely dense } \\
\text { opacity }\end{array}$ & Severe & Severe & $\begin{array}{l}\text { Maximum reach less than } \\
1 / 3 \text { the distance }\end{array}$ & Absent & 24 & $>75 \%$ \\
\hline B-4 & OD & Absent & $\begin{array}{l}\text { Severely dense } \\
\text { opacity }\end{array}$ & Moderate & Severe & $\begin{array}{l}\text { Maximum reach between } \\
1 / 3 \& 2 / 3 \text { the distance }\end{array}$ & Absent & 17 & $50-75 \%$ \\
\hline B-5 & OS & Absent & $\begin{array}{l}\text { Severely dense } \\
\text { opacity }\end{array}$ & Mild & Severe & $\begin{array}{l}\text { Maximum invasion to the } \\
\text { center }\end{array}$ & Absent & 12 & $50-75 \%$ \\
\hline B-6 & OS & Sluggish & Faint corneal haze & Mild & Absent & $\begin{array}{l}\text { Maximum reach more } \\
\text { than } 2 / 3 \text { the distance }\end{array}$ & Absent & 3 & $>75 \%$ \\
\hline B-7 & OD & Absent & $\begin{array}{l}\text { Severely dense } \\
\text { opacity }\end{array}$ & Mild & Moderate & $\begin{array}{l}\text { Maximum reach more } \\
\text { than } 2 / 3 \text { the distance }\end{array}$ & Absent & 0 & $50-75 \%$ \\
\hline B-8 & OS & Absent & $\begin{array}{l}\text { Moderately dense } \\
\text { opacity }\end{array}$ & Mild & Moderate & $\begin{array}{l}\text { Maximum reach less than } \\
1 / 3 \text { the distance }\end{array}$ & Absent & 13 & $50-75 \%$ \\
\hline
\end{tabular}

chamber view by day 60 after surgery. Maximum corneal clarity was recorded in group A by the end of 60 days. Conjunctival hyperaemia was lower in group A than in group B by day 60 (Fig. 2d). No significant difference in fluorescein dye uptake by cornea was observed in both groups post-DPSIS graft (Fig. 2e). Tear production was significantly more $(\mathrm{p}<0.05)$ in group A preoperatively and on $15^{\text {th }}$ day. Tear production in group B reached near normal values by 60 days (Fig. 2f). Digital photographic images of corneal wound healing post DPSIS grafting showed corneal pigmentation in most of the cases in group B post DPSIS grafting as compared to group A (Fig. 3 a $\& 3 b)$. KCS related corneal ulcer was identified mostly in pug breed of dogs ((John et al., 2018). Advanced disease and corneal defect almost obscured vision in group B dogs wherein KCS was identified as inherent pathology behind corneal ulcer. Corneal clarity was regained in group A post DPSIS graft. DPSIS was found integrated with corneal tissue in both groups but group B developed pigmentation obscuring view to anterior chamber. Similar observation with SIS graft was observed by other workers also, wherein existing corneal pigmentation was found augmented after corneal reconstruction with SIS graft (Turner et al., 2007; Bustin, 2002). Corneal pigmentation was a known comorbidity of KCS in dogs. Despite successful corneal 

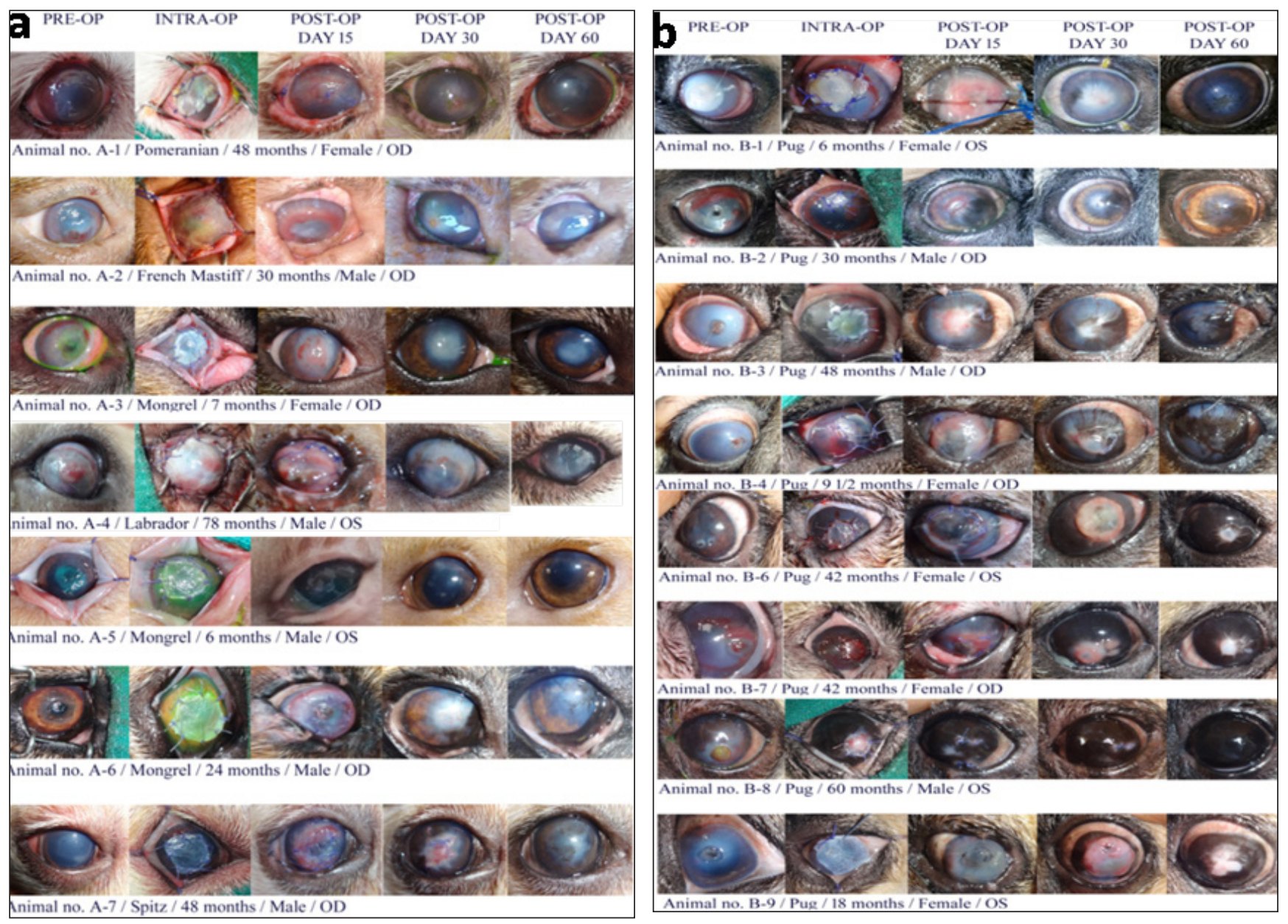

Fig. 3: Colour photographs of corneal wound healing in group A (a) before and after DPSIS graft on days 15, 30 and 60 and Colour photographs of corneal wound healing in group B (b) before and after DPSIS graft on days 15, 30 and 60

reconstruction, $\mathrm{KCS}$ pathology and corneal pigmentation advanced unhindered in KCS affected dogs.

SYBR Green based real time qRT-PCR assay targeting ICAM-1, VCAM-1, PDL1 and FASL genes were successfully standardized in the present study at an annealing temperature of $56^{\circ} \mathrm{C}$. Results were analysed by observing amplification curves, their $\mathrm{Ct}$ values and final confirmation was done by melting curve analysis. Primer pairs used for this study were designed using software IDT PrimerQuest ${ }^{\circledR}$ Tool (Table 2). GAPDH was used for normalization of data for variation in quality and concentration of input RNA. Average normalized control ct value (Avg $\Delta \mathrm{Ct}$ control) was used for calculating relative changes in ICAM-1, VCAM-1, PDL1 and FASL gene expression. Relative gene expression in each sample was calculated using the $2^{-\Delta \Delta C T}$ method with control group as calibrator and the $\log _{2}$ fold change was plotted. ICAM-1 and VCAM-1 was found up-regulated in group $\mathrm{B}$, significantly $(\mathrm{p}<0.05)$ on $30^{\text {th }}$ and $15^{\text {th }}$ day after DPSIS grafting respectively (Fig. $4 a \& 4 b$ ). Similar results of increased protein expression were found by western blotting of tear fluid proteins by ICAM-1 and VCAM-1 antibody. The expression of VCAM-1 was significantly high $(\mathrm{P}<0.05)$ in group $\mathrm{B}$ as compared to group $\mathrm{A}$ on day 15. PD-L1 was found to be up-regulated in group A and group $\mathrm{B}$ before and after DPSIS grafting on day 15, 30 and 60. The expression of PD-L1 was significantly high $(\mathrm{P}<0.05)$ in group $\mathrm{B}$ animals as compared to group $\mathrm{A}$ before grafting (Fig. 4c). FASL expression was largely 
Table 2: Primer pair sequences used for real time quantitative PCR

\begin{tabular}{|c|c|c|c|c|}
\hline Gene & Sequence of the primer & $\mathbf{T}_{\mathrm{m}\left({ }^{\circ} \mathrm{C}\right)}$ & Product length (bp) & Reference \\
\hline \multirow[t]{3}{*}{ GAPDH } & F-5' TGACACCCACTCTTCCACCTTC 3' & 58.8 & 105 & Nam et al. 2015 \\
\hline & R-5' CGGTTGCTGTAGCCAAATTCA 3' & 56 & & \\
\hline & R-5' GGCAGGTACTTGGCATACTT 3' & 54.8 & & \\
\hline \multirow[t]{2}{*}{ ICAM-1 } & F-5' AGGGCACAGTTCCAACTAAAT 3' & 54.4 & 110 & Self designed \\
\hline & R-5' TCCCGGGTCTGGTTCTT 3' & 55.8 & & \\
\hline \multirow[t]{2}{*}{ VCAM-1 } & F-5' CTTGTTTGCCGAGCACAATTA 3' & 54.1 & 101 & Self designed \\
\hline & R-5' GTGTTCCTGGGTGAGATGTAG 3' & 54.8 & & \\
\hline \multirow[t]{2}{*}{ PD-L1 } & F-5' AGGACCTGTATGTGGTAGAGTAT 3' & 54.3 & 107 & Self designed \\
\hline & R-5' CTCCATTTCCCAGTAGACGATTAG 3' & 54.6 & & \\
\hline \multirow[t]{2}{*}{ FASL } & F-5' CAACTCAAGATCCATCCCTCTG 3' & 55 & 88 & Self designed \\
\hline & R-5' CACAAGGCCACCCTTCTTAT 3' & 54.9 & & \\
\hline
\end{tabular}

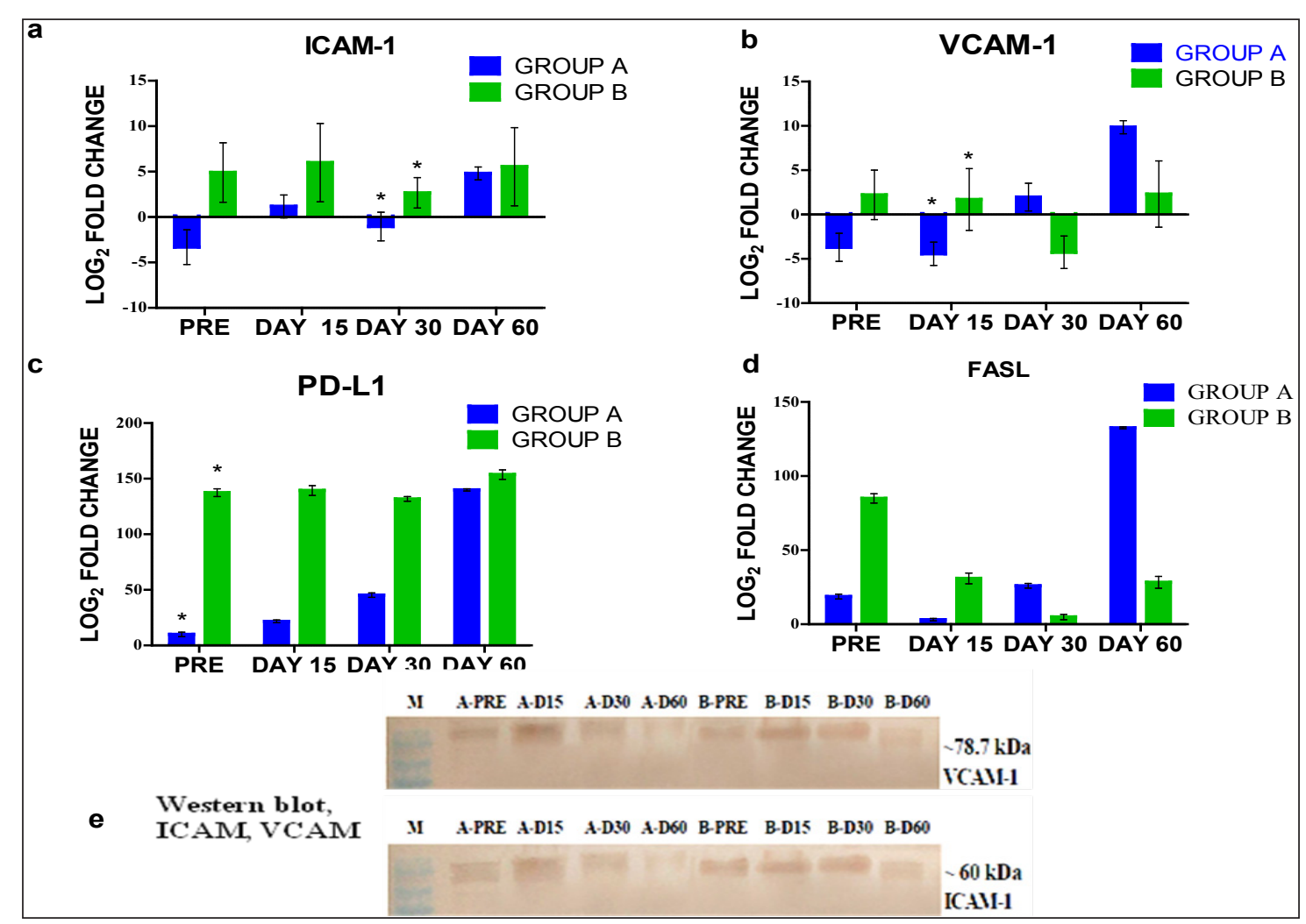

Fig. 4: mRNA expression of ICAM-1(a), VCAM-1(b), PD-L1(c) and FasL (d) in ocular surface epithelial cells in group A and Group $\mathrm{B}$ before and after DPSIS grafting on days 15,30 and 60 by quantitative real time PCR (log -fold change is depicted with standard error of difference, $\mathrm{p}<0.05$ ) and western blot for proteins ICAM-1 and VCAM-1 in tear collected from Group A and Group B before and after DPSIS grafting on days 15, 30 and 60 (f)

variable in both groups, but was found up-regulated in group A on $60^{\text {th }}$ day after DPSIS grafting (Fig. 4d).

Real-time RT-PCR has been recognised as a sensitive method of quantifying mRNA transcripts (Morita et al.,
2015). Efficient normalisation of the genes of interest was achieved with GAPDH (Kobayashi et al., 2005). ICAM-1 and VCAM-1 were found to be up regulated in KCS related corneal ulcer pre-op and on $30^{\text {th }}$ day post 
DPSIS grafting. Increased expression of cell adhesion molecules ICAM-1and VCAM-1 in corneal ulcer due to KCS was confirmed by western blotting which could be due to persistent inflammation in ocular surface in $\mathrm{KCS}$ cases. Corneal neovascularisation which persisted in graft bed after surgical reconstruction might be the source of increased VCAM in ocular surface epithelial cells. Higher mRNA expression of PD-L1 and FasL was found in ocular surface epithelial cells collected from group B compared to group A. Moderate expression of PD-L1 was observed on ductal and acinar epithelial cells of salivary gland from SS patients (Kong et al., 1997). Programmed death $-1(\mathrm{PD}-1)$ is a transmembrane protein which after engagement with its ligand PD-L1 induced down regulation of immune response and peripheral immune tolerance in corneal epithelium (Hori et al., 2006; Shen et al., 2007). Consistently enhanced expression of PDL1 in autoimmune mediated disease like KCS before and after DPSIS graft pointed towards escape from immune response and is relevant to T cell chemotaxis (El Annan et al., 2010) hence of increased significance in DPSIS graft uptake. FasL is an immune check-point which mediates $\mathrm{T}$ cell apoptosis and was found constitutively up-regulated in cornea (Hori et al., 2000). Engagement of FasL with Fas expressing cell and ensuing apoptosis is imperative for the survival of allograft in cornea (Hori et al., 2000). Higher Fas and FasL expression were identified in SS salivary glands, mostly acinar epithelial cells, which showed higher apoptotic cell death whereas the number of lymphocytes expressing FasL and apoptosis was meagre (Hori et al., 2000). FasL expression was high in Group B was higher in initial 2 weeks following DPSIS graft; but diminished subsequently. This observation suggested diminished apoptotic response to lymphocyte chemotaxis and persistence of inflammation in KCS affected cornea following grafting. Western blot analysis also showed that ICAM-1 protein expression was found increased in the tear fluid of group B compared to group A, before and after grafting on days 15,30 and 60 . VCAM-1 protein expression was also found increased in both the groups after grafting on days 15 and 30 (Fig. 4f).

\section{CONCLUSION}

Immune response to DPSIS graft in dogs suffering from Keratoconjunctivitis Sicca was explored clinically as well as through mRNA expression of relevant genes of ocular surface which were putative markers of graft bed inflammation, immunity and apoptosis; our study results implied altered immune response to DPSIS graft in KCS affected dogs. Clinically DPSIS was well integrated in corneal tissue and ensued corneal clarity in control dogs whereas corneal opacity and pigmentation was observed in KCS affected dogs post graft. Success of DPSIS grafts for repair of corneal epithelial defects and their integration into graft bed can vary due to altered immune response of graft bed post DPSIS graft in canine Keratoconjunctivitis sicca.

\section{ACKNOWLEDGEMENTS}

Authors of this manuscript gratefully acknowledge Department of Biotechnology, Government of India (DBT vide G.O. No. BT/ADV/Canine Health/ GADVASU/2017-18) for financial support. Authors also acknowledge laboratory support and facilities offered by various divisions of ICAR-Indian Veterinary Research Institute, Izzatnagar, Bareilly, Uttar Pradesh, India.

\section{REFERENCES}

Amouzegar, A., Chauhan, S.K. and Dana, R. 2016. Alloimmunity and tolerance in corneal transplantation. J. Immunol., 196: 3983-3991

Bustin, S.A. 2002. Quantification of mRNA using real-time reverse transcription PCR (RT-PCR): trends and problems. $J$. Mol. Endocrinol., 29: 23-39.

Chelladuraai, S., Singh, K., Gopinathan, A. and Agrawal R. K. 2019. Evaluation of three different impression cytology techniques for RNA retrieval from canine ocular surface epithelial cells. Res. J. Biotechnol., 14(10): 2278-4535

El Annan, J., Goyal, S., Zhang, Q., Freeman, G.J., Sharpe, A.H. and Dana, R. 2010. Regulation of T-cell chemotaxis by programmed death-ligand 1 (PD-L1) in dry eye-associated corneal inflammation. Invest. Ophthalmol. Vis. Sci., 51: 3418-3423.

Featherstone, H.J., Sansom, J. and Heinrich, C.L. 2001. The use of porcine small intestinal submucosa in ten cases of feline corneal disease. Vet. Ophthalmol., 4: 147-153.

Goulle, F. 2012. Use of porcine small intestinal submucosa for corneal reconstruction in dogs and cats: 106 cases. $J$. Small Anim. Pract., 53: 34-43.

Hori, J., Joyce, N.C. and Streilein, J.W. 2000. Immune privilege and immunogenicity reside among different layers of the mouse cornea. Invest. Ophthalmol. Vis. Sci., 41: 3032-3042. 
Hori, J., Wang, M., Miyashita, M., Tanemoto, K., Takahashi, H., Takemori, T., Okumura, K., Yagita, H. and Azumae, M. 2006. B7-H1-induced apoptosis as a mechanism of immune privilege of corneal allografts. J. Immunol., 177: 5928-5935.

John C., Gopinathan A., Singh, K., Sharma, P., Sowbharenya, C. and Sarangom, S.B. 2018. Clinical evaluation of topical tacrolimus ointment usage in different stages of keratoconjunctivitis sicca in dogs. Turk. J. Vet. Anim. Sci., 42: 259-268.

John, C., Gopinathan, A., Singh, K., Sharma, P., Sowbharenya, C. and Sarangom, S.B. 2018. Clinical evaluation of topical tacrolimus ointment usage in different stages of keratoconjunctivitis sicca in dogs. Turk. J. Vet. Anim. Sci., 42: 259-268.

John, C., Gopinathan, A., Singh, K., Sowbharenya, C., Kumar, N., Sahoo, M., and Agrawal, R.K. 2020. Conjunctival Immunocytochemistry with Interferon Gamma and Caspase 3 for Clinical Staging of Keratoconjunctivitis Sicca (KCS) in Dogs. Int. J. Curr. Microbiol. App. Sci. 9: 2952-2961

Kobayashi, M., Kawano, S., Hatachi, S., Kurimoto, C., Okazaki, T., Iwai, Y., Honjo, T., Tanaka, Y., Minato, N., Komori, T., Maeda, S. and Kumagai, S. 2005. Enhanced expression of programmed death-1 (PD-1)/PD-L1 in salivary glands of patients with Sjögren's syndrome. J. Rheumatol., 32: 21562163.

Kong, L., Ogawa, N., Nakabayashi, T., Liu, G.T., D’Souza, E., McGuff, H.S., Guerrero, D., Talal, N. and Dang, H. 1997. Fas and Fas ligand expression in the salivary glands of patients with primary Sjögren's syndrome. Arthritis Rheum., 40: 8797.

Kropp, B.P. and Cheng, E.Y. 2000. Bioengineering organs using small intestinal submucosa scaffolds: in-vivo tissueengineering technology. J. Endourol., 14: 59-62.

Kumar, A., Gopinathan, A., Singh, K., Sasikala, R. and Swapana, C.R. 2020. Effect of tacrolimus treatment on tear fluid cytokines of Keratoconjunctivitis sicca affected dogs. Int. J. Curr. Microbiol. App. Sci., 9(9): 3347-3356.
Moore, P.A. 2003. Diagnosis and management of chronic corneal epithelial defects (Indolent corneal ulcerations). Clin. Tech. Small Anim. Pract., 18: 168-177.

Morita, M., Fujita, N., Takahashi, A., Nam, E.R., Yui, S., Chung, C.S., Kawahara, N., Lin, H.Y., Tsuzuki, K., Nakagawa, T. and Nishimura, R. 2015. Evaluation of ABCG2 and p63 expression in canine cornea and cultivated corneal epithelial cells. Vet. Ophthalmol., 18: 59-68.

Sangeetha, P., Maiti, S., Sharma, N.K., Singh, K., Gopinathan, A., Ninu, A., Remya, V., Sivanarayanan, T., Mohsina, A., Mohan, D. and Mahan, P.T. 2016. Development of bioengineered corneal matrix for reconstructive surgery of eye. Trends Biomater. Artif. Organs., 30: 85-89.

Shen, L., Jin, Y., Freeman, G.J., Sharpe, A.H. and Dana, M.R. 2007. The function of donor versus recipient programmed death-ligand 1 in corneal allograft survival. J. Immunol., 179: 3672-3679.

Singh, K., Gopinathan, A., Sangeetha, P., Kumar, N. and Singh, K.P. 2016. Development and clinical application of decellularized porcine SIS and cornea for the repair of corneal defects in animals. Indian J. Anim. Sci., 86: 1391-1395.

Sowbharenya, C., Singh, K., Gopinathan, A. and Sarangom, S.B. 2019. Decellularized porcine small intestinal submucosa for the repair of deep corneal ulcer in dogs. Int. J. Adv. Res. Biol. Sci., 9: 14-18.

Swapana, C.R., Gopinathan, A., Singh, K., Sasikala, R., Kumar, A., Chelladuraai, S., Kumar, N., Sahoo, M. and Agrawal, R.K. 2020. Down-regulation of rho GTPase-activating protein 7 (DLC1) in tear film and modulation of rho GTPase dynamics by Rosuvastatin in dogs suffering from keratoconjunctivitis sicca. J. Anim. Res., 10(6): 889-898.

Turner, H.C., Budak, M.T., Akinci, M.A. and Wolosin, J.M. 2007. Comparative analysis of human conjunctival and corneal epithelial gene expression with oligonucleotide microarrays. Invest. Ophthalmol. Vis. Sci., 48: 2050-2061. 